\title{
LEAN PRODUCTION DEVELOPMENT IN SMEs: A CASE STUDY
}

\author{
Jukka Majava ${ }^{1}$, Tiina Ojanperä ${ }^{2}$ \\ ${ }^{1}$ University of Oulu, Industrial Engineering and Management Research Unit, Finland \\ ${ }^{2}$ Sokeva Ltd., Finland \\ Corresponding author: \\ Jukka Majava \\ Industrial Engineering and Management Research Unit \\ University of Oulu \\ P.O. Box 4610, FI-90014, Finland \\ phone: (+358) 40-754-01-31 \\ e-mail: jukka.majava@oulu.fi
}

Received: 2 February 2017 Accepted: 17 March 2017

\begin{abstract}
The competitiveness of small and medium sized enterprises (SMEs) is vital for the European economy. Also, manufacturing is often the core competence of SMEs. Adopting lean philosophy is a viable and popular approach for developing production and enabling continuous improvement. Despite the increased interest in empirical lean research, the body of knowledge about lean manufacturing development in SMEs is currently insufficient. This paper describes a study of a lean development project in a Finnish-based manufacturing SME. A current state analysis and development proposals are presented. The project applies a framework that other SMEs can utilize in identifying their problem areas and creating development proposals for their production activities. The results of the study contribute to the existing body of knowledge in lean manufacturing. In addition, managers in SMEs can utilize the study results as a reference when designing production development projects.
\end{abstract}

KEYWORDS

lean manufacturing; operations management; production; small and medium sized enterprise (SME).

\section{Introduction}

Small and medium sized enterprises (SMEs) are vitally important for the European economy [1]. Manufacturing is often a key function and competence in these enterprises [2,3]. SMEs can also be more flexible in their operations compared to large companies. However, the globalization of markets has increased cost-consciousness among customers. In addition, large companies often benefit from the economies of scale [4]. Thus, SMEs have to continuously develop their operations to sustain competiveness.

A viable and popular approach for developing production and enabling continuous improvement is to adopt the lean philosophy. Lean includes several methods and ways of thinking that aim at developing production. These are, for example, improved production flow, continuous improvement, and manufacturing products just-in-time [5-8].

Lean has been a very popular topic in the academic research in recent years [9]. Many aspects of lean have been discussed in the literature. For example, the lean supply chain literature was reviewed in [10]. However, as stated in [11], a gap between research and practice still exists in lean manufacturing. Thus, more empirical research is required. Empirical lean research has been especially popular in USand UK-based companies and in automotive, information, communication technology, and electronics (ICTE) industries. Yet, empirical research focusing on lean manufacturing in European SMEs is currently inadequate, which is a key motivation for this study. These SMEs could also gain benefits through lean implementation, which necessitates the analysis of practical projects. 
This study focuses on the manufacturing industry. The purpose of this paper is to describe the analysis of the case company's development project, which aimed to improve production by using lean philosophy. The research questions were set as follows:

1. What is the current state of the case company and its development needs for production?

2. How can production be improved by using lean manufacturing principles?

The research questions are addressed through literature findings and empirical analysis. The empirical part of the paper presents an analysis of the case company, which includes a current state analysis and its development needs and proposals for production. The empirical data was collected from multiple sources and included observation, company reports, and interviews with employees. The paper is structured as follows: for the background of the empirical study, the literature on lean manufacturing and lean manufacturing development is reviewed. Then, the research method is explained. The case description and analyses are presented in the results section. Finally, the results are discussed from theoretical and managerial perspectives and the study conclusions are presented.

\section{Literature review}

\section{Lean manufacturing (LM)}

Many of the pioneers in the development of modern production have come from the automobile industry [12]. These pioneers include, for example, Henry Ford (mass production), as well as Eiji Toyoda and Taiichi Ohno (Toyota Production System, TPS). TPS emphasizes addressing changing customer requirements, employee competencies, standardization, and the concept of teamwork. The term "lean production system" was introduced in 1988 based on a review of the TPS [13]. The terms "lean manufacturing" and "lean production" were introduced in the book The Machine That Changed the World [13].

Lean manufacturing is closely related to just-intime (JIT) production [14] and TPS. The relationship between lean, JIT, and TPS can be depicted as follows. Lean is a management philosophy that focuses on adding value, eliminating waste in processes, and meeting customer needs. JIT aims to improve (logistical) activities and eliminate problems in production. TPS is a business philosophy that emphasizes continuous improvement, employee learning and empowerment, and standardized work methods [15].
In spite of their manufacturing origin, lean principles have also been applied in many other sectors, including, for example, construction, software, and healthcare $[11,16,17]$. Over the years, the body of knowledge on lean manufacturing and related areas has expanded. According to the review in [11], the majority of the studies have been conceptual. A conceptual review of lean production was presented in [18]. The review covered definitions, the key elements, and criticism of lean manufacturing. Reference [9] presented a combined review of the conceptual and practical issues of lean production. Finally, a review of empirical research on lean manufacturing was conducted in [14].

\section{LM development}

Lean development should be considered as a longterm philosophy rather than a short-term project. Lean philosophy aims to improve the value stream in a holistic way and to minimize non-value adding activities [6, 7]. Reference [12] stated that lean implementation should obey the following principles: defining the value produced for the customer, identifying value streams and eliminating waste, creating a flowing process, implementing customer-driven pull control, and aiming for perfection. The identification of value adding activities is also emphasized in [19].

TPS is based on lean principles that entail focusing on the customer, continuous improvement, waste reduction, and the tight integration of processes. TPS follows lean principles by using a PPT model: People, processes, and tools and technologies are the key cornerstones that should be in balance [20]. Continuous improvement (a.k.a. Kaizen), standardization, pull control by using Kanban cards, and JIT production are typical elements that are involved in the implementation of lean manufacturing [6-8]. The 5S method - also developed in Japan - supports lean implementation. 5S includes the following items: sort/segregate, simplify/straighten, shine/sweep, standardize, and sustain/self-discipline. Two additional items, safety and support/maintenance, are also sometimes included [15].

Identifying waste (muda) is important in lean manufacturing, since waste increases costs but does not add value for the customer. The waste classes include overproduction, waiting, transport, inventory, overprocessing, motion, and defects [7]. Unused employee creativity is also considered to be waste by some authors [21].

Reference [7] proposed a systemic, data-based approach for applying the principles of value, waste, 
and flow to the supply chain. The process involves five steps: collecting data, analyzing data, designing the change, making the change, and measuring the benefits. According to [8], an analysis of the company's current state should be the first step in leanbased development. This includes analyzing the organization's strategy, business and production processes, and value streams. The next step is to define the objective state and goals. Analysis is the basis for identifying the waste and bottlenecks in the processes. Finally, the objective state and goals should be taken into account when development needs are identified and development proposals are generated.

\section{Research method}

The research reported in this paper is based on a case study method [22]. The study began with a literature review on applying the lean philosophy to manufacturing and production development. After that, a current state analysis of the case company's production process was conducted. The data was collected through observation, accessing the company's data systems, and conducting semi-structured interviews with the employees. The questions in the interviews focused on the employees' daily and weekly tasks, challenges and development ideas, and issues in the company's production process. The last part of the study included analyzing the data, creating development plans, validating the results with the case company, and making conclusions.

\section{Results}

\section{Case description}

The case company was originally established in the 1950s and is located in Southern Finland. The company's revenue is approximately seven million euros and it employs roughly twenty people. The company focuses on importing and manufacturing paint and surface finish products. Approximately $20 \%$ of the products are manufactured in-house by using make-to-stock principles. Customers are retailers that are mainly located in Finland, and they require very short delivery times. The demand is seasonal; roughly $50 \%$ of sales occur between May and September.

The company's key business processes include customer service, marketing and sales, manufacturing, inventory management, and purchasing. Support processes include business planning, competence development, product development, and re- source management. The goal of the 6 -month development project analyzed in this study was to create a plan to achieve more productive and efficient production. The main sub-goals included retaining the competitiveness of local manufacturing, creating a profitable product portfolio, achieving continuous flow in production, and improving the workforce's competencies.

The reasons for starting the development project were the production's inflexibility and high costs that reduced the company's competitiveness. In addition, the competitors were continuously improving their competiveness, which posed a huge threat for the company's survival. In-house expertise for the development work did not exist, so the company decided to utilize external expertise and conduct a researchbased development project. The aforementioned was considered important in order to ensure that the development proposals would be objective. A key goal for the project was to achieve a state where systematic improvements could be made instead of just coping with short-term issues and survival.

\section{Current state analysis}

The current state analysis was started in May 2016 by studying and observing the case company's production. In addition to observation, the data collection included interviews and accessing data in the company's data systems. This included, for example, different reports related to raw materials, production, and sales. The production layout and processes of two production lines were analyzed and a value stream description was created. It was essential to identify the key areas that should be improved by using lean principles, tools, and methods. While quick results were aimed to be achieved, it was also understood that potential resistance from the employees should be addressed by spending time in motivating and training them. Educating the employees about lean and its benefits was considered very important, because they lacked previous lean experience. Based on the current state analysis, the key issues were identified (Table 1).

Based on the current state analysis, several forms of waste were identified. The main challenges were identified to be a large amount of work-in-process (WIP) production, a large product portfolio, and the production layout. The first issue, the large number of WIP items, resulted in extra intermediate inventory, which caused disorder in the facilities. In addition, quality issues were not identified due to these inventories. 
Table 1

The key production issues based on the current state analysis.

\begin{tabular}{l|c|l}
\hline \multicolumn{1}{c|}{ Issue } & Waste category & \multicolumn{1}{c}{ Implication(s) } \\
\hline Large WIP & Waiting and inventory & $\begin{array}{l}\text { Several intermediate piles of stock and long } \\
\text { lead times }\end{array}$ \\
\hline Stock piling up at the workstations & Inventory & $\begin{array}{l}\text { Disorder and difficult access in production fa- } \\
\text { cilities }\end{array}$ \\
\hline Disorder in the facilities & Motion & Extra time spent in finding items, safety risks \\
\hline $\begin{array}{l}\text { The equipment placement does not support } \\
\text { the production flow }\end{array}$ & Transport & $\begin{array}{l}\text { WIP items must be transferred around the fa- } \\
\text { cilities }\end{array}$ \\
\hline Difficult to find the raw materials in the stock & Motion & $\begin{array}{l}\text { Stressful for employees, less time for produc- } \\
\text { tive work }\end{array}$ \\
\hline Large product portfolio & Overproduction & Man-hours spent in setups, low profit \\
\hline Large amount of different raw materials & Inventory & High ordering and holding costs, lack of space \\
\hline Employees' competencies not used & Unused employee creativity & $\begin{array}{l}\text { Low motivation, lack of development sugges- } \\
\text { tions }\end{array}$ \\
\hline Lack of up-to-date information & Defects & $\begin{array}{l}\text { Extra time spent in finding the correct infor- } \\
\text { mation, inefficiency, reworking }\end{array}$ \\
\hline
\end{tabular}

The current state analysis also demonstrated that the company's portfolio included over one hundred different products. The large amount of product variants was partly causing large WIP production. In addition, the employees specialized in certain tasks and their absences increased WIP production. The sales volumes for many products were low, but in order to meet the customers' delivery time requirements, the low-volume products had to be manufactured by using the make-to-stock approach. Over $90 \%$ of the product volume was produced with only $20 \%$ of the production equipment; thus, several machines had very low utilization rates. Decisions on the production lot sizes and sequences were affected by the previous year's demand, but the forecasts were not accurate, which caused under-production for some items and over-production of others.

The production flow was not smooth enough. Items were transferred several times between workstations during the production process. Production setup times were also quite long. This was partly due to disorder in the facilities; a lot of time was spent searching for production tools and in some cases the tools had to be repaired before use. In addition, the utilization rates for some of the machines were very low. The setup times for these machines were long, which led the management to increase the lot sizes. Product lot sizes varied between 3,000 and 10,000 units.

Raw materials were ordered in large amounts to cover demand for several months. This increased the inventory holding costs and the risk of having obsolete items, and caused disorder in the facilities. The disorder, in turn, caused the employees to spend time searching for items, resulting in production stoppage and creating frustration. A standard way to store items in the facilities did not exist. Finally, employ- ees' competencies were not fully utilized and several issues existed with the information flow and using old and invalid information.

\section{Development needs and proposals}

After the current state analysis, the objective state and goals were set for the company's production. The aim was to remove all non-value adding activities from the production process. Value stream mapping and related tools were utilized to standardize activities and improve the production flow, layout, and cycle and setup times. The 5S method and continuous improvement were also identified as important to achieve the objectives that were set. Figure 1 illustrates the case company's objective state and goals.
Current state
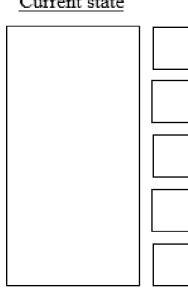

Goals

\begin{tabular}{|c|}
\hline Lower production costs \\
\hline Removal of nonprofitable products \\
\hline Shorter throughput time \\
\hline Removal of bottlenecks \\
\hline Development oriented culture \\
\hline
\end{tabular}

Objective state Competitive local production Profitable product portfolio Continuous-flow production Competent workforce
Fig. 1. The case company's objective state and goals.

The removal of non-value adding activities was identified as a key element in the development of production. For example, two assembly lines in the main production line had lower throughput than packaging; thus, a need to elevate bottlenecks was recognized. The decision was made to remove unnecessary and time-consuming activities by implementing a new layout and adopting the $5 \mathrm{~S}$ method. Table 2 presents a summary of the development needs and proposals. 
Management and Production Engineering Review

Table 2

Development needs and proposals for the case company.

\begin{tabular}{c|c|l}
\hline Development need & Waste category & Proposal \\
\hline Large WIP & Waiting and inventory & $\begin{array}{l}\text { Finalizing the product being produced before } \\
\text { moving on to a different one }\end{array}$ \\
\hline Layout & Transport & Renewed layout with smooth production flow \\
\hline Product portfolio & Overproduction & $\begin{array}{l}\text { Smaller portfolio with profitable products } \\
\text { Removal of unnecessary equipment }\end{array}$ \\
\hline Human resources & Waiting and unused employee creativity & Re-allocation, training, and task rotation \\
\hline Disorder in production facilities & Motion & 5S implementation \\
\hline Packaging materials & Overprocessing & Change in packaging materials
\end{tabular}

Decreasing WIP production was considered to be an effective way to tackle some of the problems presented above. Finalizing a production lot before starting the next one results in shorter lead times and smaller intermediate inventories. This, in turn, makes it easier to find items in the production facilities. A renewed layout reduces unnecessary movement and ensures smooth production flow. The discontinuation of nonprofitable products - approximately $50 \%$ of the portfolio - improves profitability and enables getting rid of unnecessary machine resources in production (i.e., $40 \%$ of the current equipment).

Human resources was also identified as a key area needing development. One of the key issues identified in the current state analysis was the high specialization of the production employees, which made the production process vulnerable, since the absence of one employee could prevent producing certain products. This issue was planned to be tackled with resource re-allocation, training, and task rotation. Disorder in the production facilities would be addressed with 5S implementation. Required tools and their storage locations were defined at each workstation. Finally, a proposal was made to change the packaging materials for the final products from cardboard boxes to plastic bags in cases where the old material was not considered to add any value compared to plastic. This change results in material cost savings and enables automatization.

The development proposals were planned to be implemented in the following order. First, the product portfolio renewal is carried out, which enables getting rid of unnecessary production equipment and improves the utilization of human resources. Second, the production layout is improved; this aims for continuous flow in production, the minimization of waste related to motion and transport, and the removal of unnecessary interim production phases. Third, the $5 \mathrm{~S}$ implementation targets to getting rid of unnecessary tools and items and disorder. Fourth, the employees are trained for the new working methods and tasks. Fifth, continuous improvement is carried out; every employee seeks for ways to improve productivity and well-being at work.

\section{Challenges during the project}

The development project included various challenges. At the beginning of the project, a lot of time was spent in analyzing the case company's production processes, supply chain, and product portfolio. The project planning was challenging, since the exact scope could not be defined before the current state analysis was complete and the key problem areas were identified.

One typical challenge in lean development is to identify and select the most appropriate tools and methods that suit the company's needs. Although processes and working methods should be changed and harmonized, actual implementation is recommended to be carried out in small steps, since implementing large and rapid changes in an organization can result in failure. The aforementioned issue affected the creation of the development proposals for the case company; for example, it was decided that changes in the production lot sizes toward customerdriven, pull control based production would be examined after other development needs had been addressed and the new operating procedures had become a daily practice.

\section{Discussion}

This study presented and analyzed the results of the case company's development project, which aimed to improve production by using the lean philosophy. A current state analysis was conducted, development needs were identified, and development proposals were created. A literature review on lean manufacturing and lean manufacturing development provided the background for the empirical study. The purpose of this section is to discuss the study findings from theoretical and managerial perspectives. 
The results of the study indicated several waste classes in the case company's production (Table 1). These waste classes included waiting, inventory, motion, transport, overproduction, unused employee creativity, and defects. The findings corresponded to the common waste classes discussed in the lean literature [7, 21], except for overprocessing, which was not identified during the current state analysis phase. Inventory, mainly due to large WIP production, was identified to be the most common waste class in the case company.

The development project followed the principles described in the literature review section; the objective state and goals were defined after the current state analysis (Fig. 1). The objective state and goals were taken into account in the development needs and proposals (Table 2). Removing non-value adding activities, creating a new layout, and adopting the $5 \mathrm{~S}$ method were identified as the key elements in the development work.

\section{Theoretical implications}

In spite of a large body of knowledge about the field of lean manufacturing (e.g., [18]), a need exists for further empirical research [14]. Most of the previous empirical studies have focused on US- and UK-based companies and on firms in automotive and ICTE industries. SMEs are typically considered to be lean in nature during the start-up phase. However, many types of SMEs exist and not all of them are created based on the lean principles; furthermore, their ways of operating change and their processes may become less lean during later development stages [23-25]. In a manufacturing SME, the investment made in the production equipment and the production process may reduce the flexibility of the operations. This necessitates applying new approaches to develop the company. The case analyzed in this study indicated that lean development is also beneficial for manufacturing SMEs, since applying the lean philosophy provides a systematic way to develop production activities. Several forms of waste were identified in the case company, and these findings correspond well with the common waste classes discussed in the lean literature [7, 21].

The development project followed the principles described in [8]. Although the implementation of the development proposals was not included in this study, the study results indicate that the principles can be applicable to manufacturing SMEs.

In contrast to [26], the management in the case company embraced lean thinking. The management was also keen to provide information for research purposes. However, the results of this study appear to be in line with the findings by [26], who stressed the importance of leadership and management, finance, skills and expertise, and organization culture for the successful implementation of lean manufacturing in SMEs.

In this study, lean manufacturing implementation was proposed to be carried out in small steps. Earlier research (e.g. [27]) highlights the importance of comprehensive adoption of lean practices rather than a piecemeal approach. Reference [27] presents numerous lean manufacturing elements that require a small investment, are feasible to implement, and can be recommended for SMEs. These include set up time reduction, visual control, cell layout, standardized operation, Kanban, continuous flow, uniform workload, small lot size, TQM/TQC, continuous improvement, 5S, quality circle, multifunctional employee, training, teamwork, supplier management, and preventive maintenance. In this case study, the visual control, small lot size, TQM/TQC, quality circles, supplier management, and preventive maintenance were not among the elements in the first phase of the lean implementation. In [27] it is further argued that lean practices that require least financial investment include 5S, visual control \& display, standardization of operation, Statistical Process Control (SPC), and quality circle. Thus, SMEs are recommended to apply those practices first, followed then by other practices, such as Kanban and small lot sizes. The aforementioned can be seen to be somewhat in line with the findings of this case study. Yet, for example the $\mathrm{SPC}$ requires sufficient and accurate data about the production process, which can be a challenge for the SME.

The results of this study support the previous observation by [28] who recommended the utilization of outside expertise to fill the knowledge gap in lean implementation. Furthermore, [28] stated that countrydependent cultural issues can cause challenges. For example, Indian managers tend not to use systematic management tools. However, this could also be a common problem for SMEs, which does not depend on the location.

\section{Managerial implications}

Lean philosophy can provide many benefits for manufacturing SMEs. However, the results of this study indicate that lean-based development necessitates sufficient knowledge and understanding of lean manufacturing. It should also be noted that the knowledge of lean itself is not sufficient; production development necessitates broad knowledge of operations and supply chain management and related topics, such as process management, product portfolio 
management, setup times, cycle times and throughput, layout design, pull control, and JIT. Meeting these knowledge and competency requirements can be a challenge for SMEs, which typically have a lack of resources. External consultation, training, and recruitment may therefore be preconditions for the development work. The availability of proper data should also be ensured (e.g., [29]).

The study results also indicate that enough time should be reserved for the current state analysis; this includes several aspects, such as an analysis of the company's production processes, supply chain, and product portfolio. The problem areas can only be identified after a careful current state analysis. It should also be stressed that the same tools and methods may not be appropriate for all SMEs. Finally, although the implementation of the development proposals was not included in this study, some words of advice should be given. As pointed out in previous studies, for example, in [7], lean implementation should be carried out in small steps. In addition, the company's management has a key role in the lean implementation. For further discussion of the management's role, see, for example, [5].

Reference [30] argues that some special requirements should be considered when designing a framework for business process improvements in SMEs. The findings of this study resonate with this statement. Especially, the following recommendations by [30] can be considered important for the success of the case company's lean development project: the ability to demonstrate quick initial results, simplicity and practical orientation, utilization of the company's strengths, and taking resource implications into account.

\section{Conclusions}

The competitiveness of manufacturing SMEs is vital for the European economy. Lean philosophy has proven to be a viable and popular approach for developing production processes and enabling continuous improvement in these companies. Despite a great interest among academics and practitioners, more empirical research on lean manufacturing development in European SMEs is needed.

This paper described a study of a lean development project in a Finland-based manufacturing SME. A current state analysis and development proposals were presented. The main challenges in the case company were a large amount of WIP production, a large product portfolio, and an unproductive production layout. These challenges were addressed with development proposals based on lean manufac- turing principles. The development project followed a literature-based framework. The framework proved applicable to the case company; the results indicate that SMEs can benefit from the framework when creating lean-based development proposals. The study results can assist managers in SMEs in the proper planning of lean-based production development projects.

The limitations of this study include the typical limitations of a single case study, including validity and reliability concerns. These concerns were addressed by using multiple data collection methods and careful analysis, and by validating the findings in the case company. However, the generalization of the findings based on a single case would be difficult. Furthermore, the implementation of the development proposals was not included in the study. This calls for further research on the performance implications related to, for example, the new layout. Recommended future studies, besides addressing the aforementioned limitations, could include how well the findings of this study apply to various types of SMEs operating in other sectors and different parts of the value chain. Especially the service industry should be addressed in the future due to its growing economic importance.

\section{References}

[1] European Commission, The new SME definition - user guide and model declaration, Enterprise and Industry Publications, Brussels, 2005, Accessed 1 February, 2017. Available at: https://ec.europa.eu/digital-single-market/en/news /new-sme-definition-user-guide-and-modeldeclaration.

[2] Cagliano R., Spina G., A comparison of practiceperformance models between small manufacturers and subcontractors, International Journal of Operations \& Production Management, 22, 12, 1367-1388, 2002 .

[3] Löfving M., Säfsten K., Winroth M., Manufacturing strategy frameworks suitable for SMEs, Journal of Manufacturing Technology Management, 25, 1, $7-26,2014$

[4] Panzar J.C., Willig R.D., Economies of scale in multi-output production, The Quarterly Journal of Economics, pp. 481-493, 1977.

[5] Koch T., Horbal R., Kagan R., Sobczyk T., Plebanek S., 10 commandments for the boss of a company implementing Lean philosophy, Management and Production Engineering Review, 3, 2, 62-78, 2012. 
[6] Liker J.K., The Toyota way: 14 management principles from the world's greatest manufacturer, New York, NY: McGraw-Hill, 2004.

[7] Melton T., The benefits of lean manufacturing: what lean thinking has to offer the process industries, Chemical Engineering Research and Design, 83, 6, 662-673, 2005

[8] Rother M., Toyota Kata: managing people for improvement, adaptiveness and superior results, USA: McGraw-Hill, 2010.

[9] Pettersen J., Defining lean production: some conceptual and practical issues, The TQM Journal, 21, 2, 127-142, 2009 .

[10] Ugochukwu P., Engström J., Langstrand J., Lean in the supply chain: a literature review, Management and Production Engineering Review, 3, 4, 87-96, 2012.

[11] Vamsi Krishna Jasti N., Kodali R., A literature review of empirical research methodology in lean manufacturing, International Journal of Operations \& Production Management, 34, 8, 1080-1122, 2014.

[12] Womack J.P., Jones D.T., Lean thinking: banish waste and create wealth in your corporation, New York, NY: Simon \& Schuster, 1996.

[13] Womack J.P., Jones D.T., Roos D., The machine that changed the world, New York, NY: Rawson Associates, 1990.

[14] Sohal A.S., Egglestone A., Lean production: experience among Australian organizations, International Journal of Operations \& Production Management, 14, 11, 35-51, 1994.

[15] Heizer J., Render B., Operations management: sustainability and supply chain management, 11th edition, USA: Pearson education Ltd, 2014

[16] Landsbergis P.A., Cahill J., Schnall P., The impact of lean production and related new systems of work organization on worker health, Journal of Occupational Health Psychology, 4, 2, 108-130, 1999.

[17] Pekuri A., Herrala M., Aapaoja A., Haapasalo H., Applying Lean in construction-cornerstones for implementation, Proceedings of the 20th Annual Conference of the International Group for Lean Construction, pp. 18-20, 2012.

[18] Papadopoulou T.C., Özbayrak M., Leanness: experiences from the journey to date, Journal of Manufacturing Technology Management, 16, 7, 784-807, 2005.
[19] Pepper M.P.J., Spedding T.A., The evolution of lean six sigma, International Journal of Quality \& Reliability Management, 27, 2, 138-155, 2010.

[20] Liker J.K., Morgan J.M., The Toyota way in services: the case of lean product development, The Academy of Management Perspectives, 20, 2, 5-20, 2006.

[21] Sternberg H., Stefansson G., Westernberg E., Boije af Gennäs R., Allenström E., Linger Nauska M., Applying a lean approach to identify waste in motor carrier operations, International Journal of Productivity and Performance Management, 62, 1, 47-65, 2012.

[22] Eisenhardt K.M., Building theories from case study research, Academy of Management Review, 14, 4, $532-550,1989$

[23] Aulet W., Murray F., A tale of two entrepreneurs: understanding differences in the types of entrepreneurship in the economy, 2013, Accessed 28 March, 2017. Available at: https://ssrn.com/abstract $=2259740$.

[24] Churchill N.C., Lewis V.L., The five stages of small business growth, Harvard Business Review, 61, 3, 30-50, 1983.

[25] Majava J., Kinnunen T., Kess P., Foit D., Analysing innovation-driven enterprises' stakeholders in two spatial ICT ecoystems, International Journal of Management and Enterprise Development, (in press).

[26] Achanga P., Shehab E., Roy R., Nelder G., Critical success factors for lean implementation within SMEs, Journal of Manufacturing Technology Management, 17, 4, 460-471, 2006.

[27] Rose A.M.N., Deros B.M., Rahman M.A., Nordin N., Lean manufacturing best practices in SMEs, Proceedings of the 2011 International Conference on Industrial Engineering and Operations Management, $2,5,872-877,2011$

[28] Panizzolo R., Garengo P., Sharma M.K., Gore A., Lean manufacturing in developing countries: evidence from Indian SMEs, Production Planning \& Control, 23, 10-11, 769-788, 2012.

[29] Puurunen A., Majava J., Kess P., Exploring incomplete information in maintenance materials inventory optimization, Industrial Management \& Data Systems, 114, 1, 144-158, 2014.

[30] Khan Z., Bali R.K., Wickramasinghe N., Developing a BPI framework and PAM for SMEs, Industrial Management \& Data Systems, 107, 3, 345-360, 2007. 